\title{
A Importância do Fator Motivacional no Trabalho
}

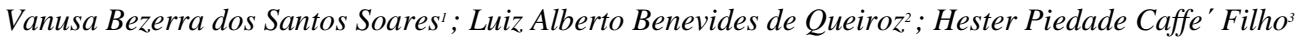

\begin{abstract}
Resumo: Este artigo objetivou analisar a importância do fator motivacional no ambiente de trabalho, se tratando de uma abordagem critica tratando das relevâncias para o contexto organizacional, na percepção de enxergar os problemas de forma que se possa busque solução deles. Assim propomos um estudo com elementos teórico para responder questionamentos sobre a importância do fator motivacional e como melhor aplicá-los na administração pública observando ainda conflitos entre os objetivos individuais e os objetivos organizacionais. A pesquisa de campo alencou uma maior importância para administração pública, objeto desse estudo, introduza estratégias no contexto que facilitem, dentre outros, o reconhecimento profissional despertando o crescimento profissional através de bons canais de comunicação e plano de cargos e salários bem como o bem estar, pois não se busca máxima eficiência e eficácia nas operações sem a garantia desses fatores influenciadores da motivação. A principal conclusão do trabalho que a desmotivação e apatia dos colaboradores é o resultado da falta de um plano Estratégico dentro da administração pública voltado para gestão de pessoas.
\end{abstract}

Palavras-Chave: Motivação. Avaliação. Reconhecimento.

\section{The Importance of the Motivational Factor at Work : a critical approach}

\begin{abstract}
This article aims to analyze the importance of the motivational factor in the workplace, in the case of a critical approach addressing the relevance to the organizational context, the perception to see the problems so that you can seek their solution. So we propose a study of theoretical elements to answer questions about the importance of motivational factor and how best to apply them in public administration still observing conflicts between individual goals and organizational goals. The field research alecou greater importance for public administration, object of this study, key strategies in the context to facilitate, among others, the professional recognition awakening professional growth through good communication channels and plan for jobs and wages and welfare because search is not maximum efficiency and effectiveness in operations without the guarantee of these influencing factors of motivation. The main conclusion that the lack of motivation and apathy of employees is the result of the lack of a strategic plan within the public administration aimed at people management.
\end{abstract}

Keywords : Motivation. Evaluation. Recognition.

\section{Introdução}

Trataremos de um artigo bastante importante para o âmbito administrativo e diante da ampla importância focaremos na gestão pública, a qual apresenta desafios de estudar a importância do fator motivacional no ambiente de trabalho e sua relevância para o contexto organizacional.

\footnotetext{
${ }^{1}$ Universidade Vale do São Francisco - UNIVASF. Autor correspondente: vanusa_bezerra@ @otmail.com;

${ }^{2}$ Possui graduação em Ciências Contábeis pela Faculdade de Ciências Aplicadas e Sociais de Petrolina (2008). Tem experiência mediana de: Finanças, contabilidade pública e gerencial. PÓS-GRADUAÇÃO: MBA, GERÊNCIA CONTÁBIL, PERÍCIA, AUDITORIA E CONTROLADORIA.

${ }^{3}$ Mestre em Gestão de Políticas Públicas. Universidade Vale do São Francisco - UNIVASF.
} 
O estudo envolve questionamento sobre qual a relevância dos fatores motivacionais no ambiente de trabalho e como aplicá-los dentro da gestão pública. Ainda contaremos com pesquisa bibliográfica, também propõe - se uma pesquisa de campo desenvolvida na área publica com personalidade de investigação, observando as opiniões dos funcionários em relação: reconhecimento pelo trabalho desenvolvido, as chances de crescimento profissional dentro do ambiente de trabalho, motivação pelo exercício de sua atividade profissional, avaliação da política de treinamento de pessoal, desempenho ou vantagens adicionais por mérito, avaliação da comunicação entre os níveis hierárquicos da empresa, avaliação dos fatores que afetam o bem-estar dentro da empresa e avaliação do clima organizacional.

A pesquisa será esmiuçada dando o maior suporte a importãncia de inserir em seu contexto estratégias que possibilitem alcançar os principais pontos: 1- O crescimento profissional, 2- Bons canais de comunicação,3-Plano de cargo e salários .Afim de que se busque a máxima eficiência e eficácia nas operaçoes, Analisando conceitos para no final deste estudo, apresentar aos gestores públicos aos quais se possam adequar a realidade, disponibilizando todo material estudado, trabalhado e formas de elaboração dos projetos a serem colocados em prática, sendo que os funcionários devem fazer parte da pesquisa de amostra de questionários porém devem ser respeitados quanto a participação verbal ou escrita, quanto as assinaturas dos participantes não será obrigatória nesta pesquisa de campo.

\section{Referencial Teórico}

Consecutivamente quando falamos em motivação, vem na tona que está psicologicamente relacionado com algo que motiva pessoas. Com essa conjuntura, alguns autores procuram definitivamente discutir tal teor a partir da observação da teoria das relações humanas em conjuntura com o seu comportamento.

Dentre estes autores, destaca-se Chiavenato (2000) com seu enfoque, que buscar abordar a identificação das suas essências e da sua contextualidade, em que na sua teoria apareceu, cuja evidência que está na pessoa ao avesso da parte estrutural ou então das tarefas, para assim relacioná-la com a ciência que estuda as relações entre pessoas que pertencem a uma comunidade ou diferentes grupos que formam a sociedade e a ciência que estuda o comportamento e as funções intelectuais, pois, como a necessidade de humanização.

Kurt Lewin, é membro no movimento que defende o cognitivista, sendo assim, uma teoria que pesquisa e analisa o entendimento da mente subjacentes opondo-se ao behaviorismo que é voltado para o comportamento humano e aperfeiçoamento do estudo da psicologia em relação aos comportamentos (OLIVEIRA, SILVA e ROLIM, 2013). 
Conforme Bergamini (2006) Lewin haja vista, que foi um percurso e contribui de modo sistemático aos estudos de motivações, que procura de modo agregada uma ampla coordenação que ao efeito do passado em questão do comportamento da atualidade.

Assim, Bergamini (2006) fala que, com a concepção de Lewin, nesse momento foi possível deixa neutro muitos critérios, porém, identificá-los. Com está acepção, o comportamento de muitas pessoas ela passar a surgir quando os indivíduos provam as mesmas emoções de forma a unir-se, conforme quando o grau de coerência passa a habilitar que adéqua com o mesmo modo de comportamento em sentido estrito.

Bergamini (2006) sistematiza os quatro pressupostos básicos de Lewin:

1. O grupo deve ser considerado como o terreno ao qual o indivíduo se mantém;

2. O indivíduo utiliza o grupo como seu instrumento para a satisfação de necessidades próprias;

3. Os valores, necessidades e expectativas pessoais podem ser gratificados ou frustrados pelo grupo;

4. "O grupo é considerado como um dos elementos do espaço vital do indivíduo. (BERGAMINI, 2006, p.13)

Nesta ocasião, com estudo apontando a grande importância de Lewin continuar a ser marcado de forma experimental como uma adaptação social, quando a pessoa formaliza com sua superação exposto das dificuldades correspondentes que venha por vim, na esfera profissional, na expectativa com suas ambições e suas atuações positivas para atingir suas finalidades no âmbito empresarial ou público.

Para Robbins (2005), ele fala que a motivação está acompanhante em um determinado artifício que seja culpado pela melhoria de uma magnitude de um profissional, e, contextualizando a com uma persistência dos esforços e determinado propósito para ser alcançado um determinado objetivo.

Como exposto, revelar, Chiavenato (1999, p. 89), "o primeiro passo para se conhecer a motivação humana é o conhecimento do que ocorre no comportamento das pessoas". Sabias palavras, ao compara com um organismo humano, pois, quando não está em equilíbrio estará em total debilitação, ou seja, em desequilíbrio.

Assim, Robbins (2005) fala que "a motivação é um impulso constante e de intensidade variável orientado para o alcance de um objetivo, seja este decorrente de uma necessidade ou de um estado de satisfação." Isso, revela que de forma explicita que a motivação pode ser acentuada como um pleno empenho, ou seja, mesmo, um interesse pessoal de um funcionário para a ação.

Como exposto, revelar, Chiavenato (1999), que as necessidades no âmbito funcional elas podem ser satisfeitas, ou pode ser também frustrada.

Assim, a motivação no ambiente de trabalho tem raízes no indivíduo, de tal modo na organização como no ambiente externo e na própria situação além da empresa devemos observar a 
Id on Line Revista Multidisciplinar e de Psicologia

Id on Line Multidisciplinary and Psychology Journal

situação do país e do mundo em certas situações. Prontamente, os agentes que podem interferir na motivação muitas vezes podem ser externos às pessoas, ou podendo ser internos, ou de forma inconsciente, ou então dos anseios criados, de maneira consciente. Deste modo, quando assentadas essas ideias, podem perceber que a na motivação é um amplo impulso que decorre de dentro, seja, suas fontes subjetivas de vigor no interior de cada indivíduo. Porém, os impulsos externos do ambiente são condicionantes do comportamento de cada pessoa o que do mesmo modo que impactar o nível motivacional. (BERGAMINI e CODA, 1995)

\section{Teoria Comportamental}

Teoria comportamental é o estudo que observa o comportamento individual das pessoas, a partir da motivação humana e para isso os autores behavioristas acreditam que administrador precisa conhecer as necessidades humanas só assim entenderá o comportamento humano e usar a motivação como melhor forma de melhorar a qualidade de vida dentro da organização.

PRESSUPOST OS DA T EORIA X Y

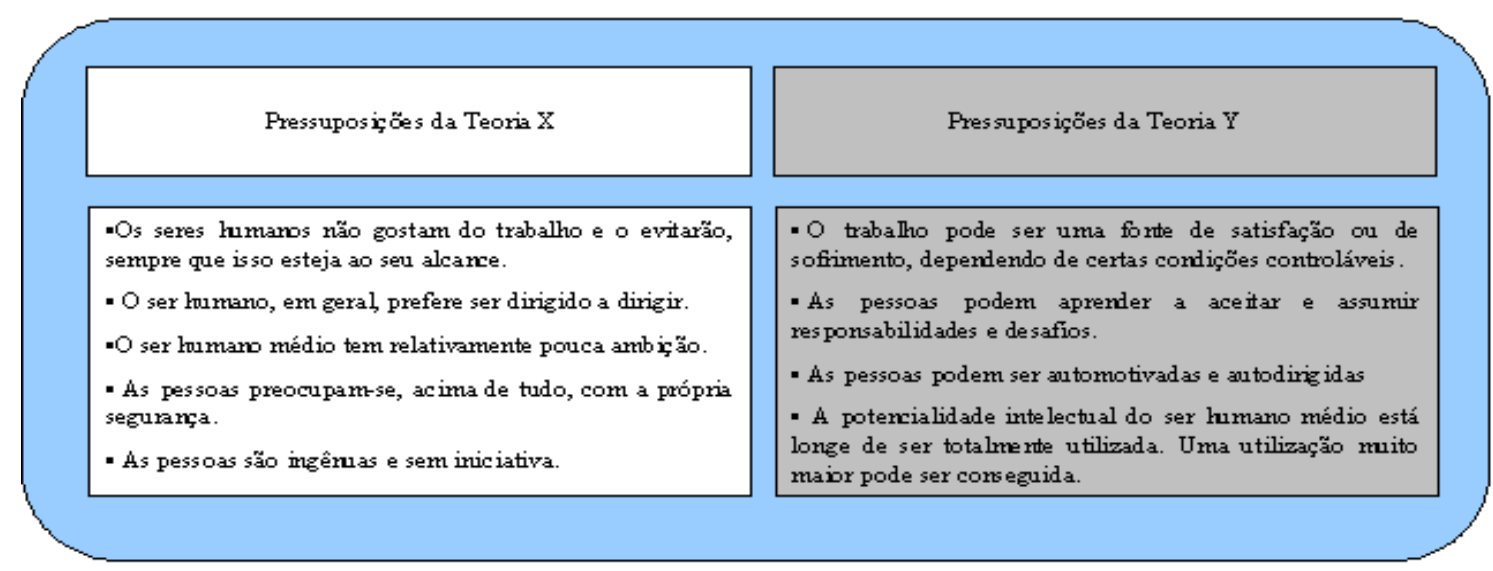

Figura 4 - Diferentes pressupostos da teoria X Y

Fonte: CHIAVENATO, Idalberto. Recursos Humanos. $3^{\text {a }}$ ed. São Paulo: Atlas, 1995.

Ainda com base nas teorias desenvolvidas por Douglas Mcgregor X e Y tipos, vejam as diferenças:

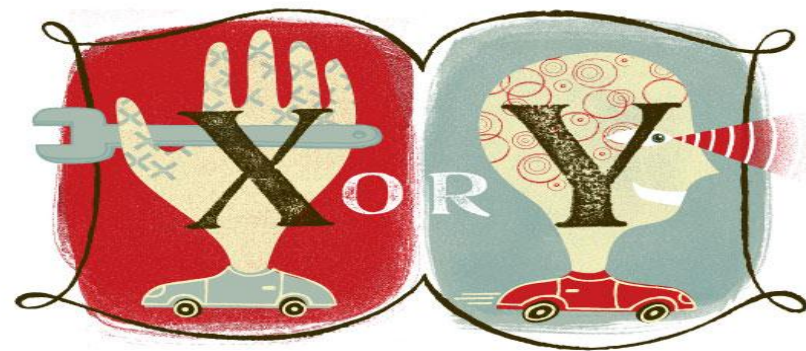


Na teoria x o funcionário é caracterizado por não gostar de trabalhar, onde pouco se motiva, para desenvolvimento de suas tarefas é necessário ordens ou acompanhamento dos seus superiores. Onde muitas das vezes os servidores necessitam ser ameaçados, coagidos e vigiados para garantir o desenvolvimento de suas tarefas em dos objetivos. (MCGREGOR, 1970)

Já a teoria y o funcionário é motivado por se mesmo e demonstra o mais de esforço para assumir suas responsabilidades colaborando o máximo possível, opinando e participando das decisões e crescimento da sua organização. Os funcionários têm prazer no trabalho como também no lazer, são organizados, criativos e não necessitam de ameaças para desenvolverem suas responsabilidades as quais também lutam por benefícios para compensar incômodos causados por tarefas pouco agradáveis. (MCGREGOR, 1970)

McGregor enxergava as necessidades inferiores como forte influência no comportamento das pessoas quais tornam uma dependência para transformação do sucesso da organização a qual se observa a criação local de trabalho da mais perfeitas condições as quais as pessoas fossem bem no trabalho por se sentirem bem, dando a gestão satisfação dos fatores higiênicos dos trabalhadores.

\section{Teoria de Hierarquia das Necessidades Humanas}

De acordo com Lawer (2000), na atualidade, em desempenho de uma democratização e da facilidade da informação, com a celeridade que se alastrar-se os conhecimentos humanos, vem destacando o comportamento humano em determinado ambiente de trabalho principalmente o meio público, tem sido mais examinado, assim, objetivando otimizando de modo objetivo o seu desempenho nas organizações pública ou provada. Com isso, o ensejo, vem destacando o comportamento da pessoa como figura a comprovar a sua importância decisiva nas organizações.

Chiavenato (2000) conseguiu estabelecer de modo explicativo uma composição para estabelecer a Hierarquia de Necessidades Humanas e seus modos de satisfação, realizada por Maslow, de modo objetivo certifica que todas as pessoas são impulsionadas, motivados, que notadamente se satisfazer nos grupos de necessidades hierarquicamente constituídas e bem trabalhadas com suas organizações. Certamente, o potencial quando atingi o seu máximo desenvolvimento através do auto realização, assim, respeitado outros indivíduos, abrigo, reconhecimento, por ter certeza da proteção perdas humanas, garantia em casos de algumas enfermidades, desastres, problemas de recursos etc.

De acordo com Chiavenato (2000) Maslow, esquematiza o perfil da pessoa que certamente que foi motivado, e de outra pessoa que não foi motivado, e com isso, observar-se que as pessoas foram motivadas repetidamente demonstram, ser bem extravagantes, bem humorados, ter facilidade com novas amizades, capacidades, energia, vitalidade. Prontamente, as pessoas determinadas quando 
não são motivadas, apresentaram um perfil de: sem produção no setor público, mal humorados, desinteressados, são difíceis de ter amizades e que são mais fechados, esses são os perfis das pessoas desmotivados

Para Chiavenato (2000), Diante, do assunto fático, o autor efetiva um ciclo motivacional, com grande finalidade de assegura as condições para que possa ter um bom contentamento para se chegar na motivação aceitável. Desde modo, devemos destacar: a) equilíbrio interno; b) estímulo ou incentivo; c) necessidade; d) tensão; e) comportamento ou ação; f) satisfação.

Quanto aos ensinamentos dos dois fatores, consistir em quer essa teoria, quando os fatores higiênicos e motivacionais foram desenvolvidos por Herzberg apud Chiavenato (2004, p. 239) alegava que "a motivação dos indivíduos depende destes dois fatores que tem ligações estritas". Que podem ser influenciadores da motivação: o intrínseco e o extrínseco ou higiênico.

Em forma, os fatores motivacionais contribuem e objetiva que tenham um atributo como no produto e também nos serviços, e com mais intuído na vida das pessoas dentro das organizações público ou privado. Com isso, melhorando o clima de trabalho, e desta forma, havendo um melhor aproveitamento em equipe e oferecendo uma inteiração social, haja vista, que melhora a auto realização na tarefa, o prestígio quanto à realização da tarefa efetivada.

Com a teoria criada por Frederick Herzberg. Que posiciona que existem dois fatores apropriados de motivar, que são os fatores extrínsecos ou higiênicos e também fatores intrínsecos ou motivadores. Devemos lembra que saudoso Vergara (2000), ele buscava nos estudos localizar quais ao certo os tipos e as suas consequências nos eventos na vida de cada profissional, e com, as pesquisas elaboradas, tentou-se verificar os fatores que alteraram a se experimentar tão-somente felizes e infelizes nas atividades elaborais.

Como trata no assunto, Dubrin (2003) diz que os fatores intrínsecos permanecem compreendidos com o cargo e também com a hierarquia do cargo ocupado e o quais as atividades que serão executadas pelos indivíduos, devemos verificar, que essas modalidades estão acentuadas com o reconhecimento e as chances de crescimento profissional na empresa. A respeito dos fatores higiênicos, indica que o ambiente deve ser dócil, e muito flexível onde serão executadas as atividades diárias de um profissional.

Assim, de acordo com os autores citados, no intuito de fornecer uma espécie de classificação, a motivação pode ser analisada de duas formas: inconsciente e inconsciente. No aspecto inconsciente, as atitudes são influenciadas por fatores de ordem alheia, estranhas ao conhecimento ou vontade do indivíduo. E é justamente esta diferenciação que se torna objeto de estudo da psicologia e outras ciências, bem como teorias, como as de Maslow e Herzberg. Logo, ambos os autores prescindem de que a satisfação inicial das necessidades primárias ou fatores higiênicos pelos colaboradores se constitui meramente na oferta das condições necessárias ao exercício do trabalho. Cabe aos empreendedores e também aos gestores públicos, por sua vez, satisfazer os fatores motivacionais dos 
seus colaboradores por meio da análise do que realmente irá lhes proporcionar auto realização e autoestima, que seja, ter um efeito bastante agradável e reduzindo o nível de estresse no ambiente de trabalho, e melhorando significamente a qualidade de vida no trabalho.

\section{Qualidade de Vida no Trabalho}

Estudos relatam que a partir da década de 1980 o tema qualidade de vida no trabalho passou a ser bastante explorado por ter sido impulsionado pela competitividade marcado também pelo desenvolvimento tecnológico ao qual despertou novas exigências em relação ao trabalho.

Nesta linha de raciocínio, LIMONGI- FRANÇA (2004) ao tratar de produtividade e dimensão humana, diz que o desafio é:" Reconstruir com bem estar, o ambiente competitivo altamente tecnológico de alta produtividade do trabalho e garantir ritmos" (p.45).

Percebe-se que a motivação está totalmente ligada a qualidade de vida no trabalho, ao qual se alinha aos valores e práticas mais recentes da gestão de qualidade de vida dentro do setor público e fora dele, pois satisfação e bem estar do individuo tem sido objeto de preocupação dos trabalhadores e das empresas que possuem consciência que tal influência garante vantagem para ambos, consideramos então que o comportamento de um indivíduo poderá ser modificado pelas necessidades de cada pessoa.

Vejamos as palavras de Matos (1996), citado por Martins (2002, p.22) diz:

Para se falar de qualidade de vida, temos de entrar no campo da motivação humana, buscando descobrir quais as necessidades do homem e que áspera com realização de vida. A qualidade de vida importa em consciência individual e social sobre o surgimento da vida para que o homem coloque sua força transformadora em realização plena. A base da discussão sobre o conceito de qualidade de vida encerra escolhas de bem-estar e percepção do que pode ser feito para atender a expectativas criadas tanto por gestores como por usuários das ações de QVT nas empresas (LIMONGI-FRANÇA, 2010, p. 24).

A vasta discussão sobre o conceito QVT e como melhor compreender de forma geral todas as dimensões sobre o tema QVT, impulsionou a autora Limongi-França (2010) a sugerir proposta de junção das teorias, com um olhar para legislação cuidados de segurança e saúde do trabalhador, fatores pessoais dos empregados e empregadores, envolvendo seus momentos de lazer e sua motivação.

A autora observa ainda que agrupando tais dimensões sobre o tema QVT torna o entendimento mais eficaz das demandas da necessidade de qualidade de vida dentro da empresa como importante avanço, através das idéias das três escolas de pensamento - Socioeconômica, Organizacional e Condição Humana no Trabalho, que dão suporte ao conteúdo em estudo da gestão da QVT. 
Escolas Idealizadas por Gildens 1998. Apud Limongi-França (2010, P.25)

\begin{tabular}{|c|c|c|}
\hline $\begin{array}{l}\text { ESCOLA } \\
\text { SOCIOECONÔMICA }\end{array}$ & $\begin{array}{l}\text { ESCOLA } \\
\text { ORGANIZACIONAL }\end{array}$ & $\begin{array}{l}\text { ESCOLA DE CONDIÇÃO } \\
\text { HUMANA NO TRABALHO }\end{array}$ \\
\hline $\begin{array}{l}\text { Idealizada principalmente por } \\
\text { Giddens (1998, apud LIMONGI- } \\
\text { FRANÇA, 2010, p. 25), institui } \\
\text { a "terceira via" como uma nova } \\
\text { maneira de pensar advinda de } \\
\text { mudanças mundiais importantes, } \\
\text { tais como a globalização, as } \\
\text { transformações ocorridas na vida } \\
\text { pessoal de cada indivíduo, e sua } \\
\text { forma de se relacionar com a } \\
\text { natureza. Assim, o autor } \\
\text { postulou, como princípios } \\
\text { básicos dessa corrente política, o } \\
\text { desenvolvimento da cidadania, a } \\
\text { responsabilidade por projetos } \\
\text { sociais, a igualdade com } \\
\text { liberdade, preservação do meio } \\
\text { ambiente, e o desenvolvimento } \\
\text { sustentável. }\end{array}$ & $\begin{array}{l}\text { (...) expansão dos processos de } \\
\text { qualidade e produtividade para o } \\
\text { de qualidade pessoal; política de } \\
\text { gestão de pessoas-valorização e } \\
\text { capacitação; marketing- imagem } \\
\text { corporativa e comunicação } \\
\text { interna; tempor livre } \\
\text { desenvolvimento cultural, } \\
\text { hábitos de lazer esporte; e risco } \\
\text { e desafio como fatores de } \\
\text { motivação e comprometimento } \\
\text { (LIMONGI-FRANÇA, 2010, } \\
\text { p.27). }\end{array}$ & $\begin{array}{l}\text { (...) mostra que a pessoa é um } \\
\text { ente biopsicossocial, que tem } \\
\text { potencialidades biológicas, } \\
\text { psicológicas e sociais e que estes } \\
\text { fatores "são fundamentais para a } \\
\text { explicação da saúde e da doença } \\
\text { da sociedade moderna" } \\
\text { (LIMONGI-FRANÇA. } \\
\text { P.28). }\end{array}$ \\
\hline
\end{tabular}

\section{Explicações psicológicas da motivação}

Quando há um bom controle nas atividades realizadas nas motivações certamente o homem produzira mais, conforme o nosso fabuloso Bergamini (1988), quando se há uma gestão com compromisso, ou seja, quando existe a eficácia insinua necessariamente numa demanda de se administrar adequadamente a motivação. Como se sabe, nesse sentindo, verá o entendimento de Castro (2005), defende que a motivação certamente de forma clara, defendendo que na medida dos poderes, é o mais empregado, assim, melhora as tarefas imposta nas atividades profissionais.

Assim, pra Costa e Boruchovitch, (2006, p. 88) lembram que "motivação em seu sentido Etimológico, pode ser entendida dentro de uma concepção semelhante a motivo", assim, para autora, esclarece que o motivo é fundamental, e que se dar no fator interno, que tudo começa a desenvolver, conduz e mesmo tempo agrega o comportamento do indivíduo, claramente isso acontece pelo sentindo ao impulso de uma recompensa. Certamente quando este motivador que é o impulso não é adquiro, percebemos que os gestores de certo modo, fala-se que os seus subordinados não terão uma motivação oportuna. Com certeza vai alcançar de modo desgastante para a empresa.

Com essa percepção, Ludington\& Graham, fala quer:

Sempre que sentimos um desejo ou necessidade de algo, estamos em um estado de motivação. Motivação é um sentimento interno é um impulso que alguém tem de fazer alguma coisa. (Rogers, Ludington\& Graham, 1997, p. 2) 
Neste sentido, compreendemos que o motivo completa quando norteia seu objetivo é claramente alcançado com uma intenção de crescimento do indivíduo. Assim, completar-se que na essência que motivar interliga as ações de comportamento humano melhorando as suas tarefas diárias e portando o seu estado emocional e assim melhorando para resolver qualquer dificuldade que tenha no ambiente de trabalho, assim certamente a pessoa vai ter novos estímulos.

Sales (2005) pontua que a motivação é uma equação que cobre três variáveis:

\section{Fazer um esforço;}

2. Manter este esforço até que o objetivo seja atingido;

3. Consagrar a ele a necessária energia.

Com isso, as pessoas têm que ter certa insistência para chegar aos pontos favoráveis, certo modo, a motivação apresenta situações de dimensão de persistência às diversidades. Com isso, verificamos que o autor pondera que a motivação surge no interior de cada pessoa e chegando ao ponto de ser uma energia propulsora que a impulsiona de certo modo para conseguir seus objetivos com consentimento trabalhando mais e de forma formidável para empresa.

Por outro lado, conforme Vergara (2000) verificou-se ao analisar, assim, foi testado algumas pessoas, aplicando algumas tarefas, com ensejo de mediar as diferentes respostas, e viu-se que a motivação é categoricamente de formato intrínseca, ou seja, nota que está dentro das pessoas, incide existir as nossas necessidades interiores.

Para a autora, o motivo que as pessoas apresentaram reações diversas entre elas em face quando é exposta a determinada tarefas e responsabilidades, pois que, existe a herança étnica ou cultural de cada pessoa. Pra que possa conduzir com essas diferenças, primeiramente o responsável tem que ter um estudo melhor pra que seja ofertado de modo igualitário com essas diferenças, isso, que vai ser o papel de um bom gestor.

\section{Proposta de Intervenção}

Inovar a administração pública não é um projeto para um dia, é uma busca persistente pelos melhores métodos para liberar e potencializar a capacidade humana. Pois nos dias atuais, cada vez mais se acentua a grande importância do comprometimento dos funcionários com o órgão público. Assim, é fundamental que os gestores conheçam o seu grau de motivação e satisfação de seus funcionários, assim, podendo inovar com reconhecimento profissional amplo que satisfaçam as necessidades de ambos incluindo.

Sugestões: A boa comunicação é fundamental para elaboração de quais quer que seja a tarefa a realizar, por isso se faz-se necessário a implantação de estratégias voltadas para uma boa 
Id on Line Revista Multidisciplinar e de Psicologia

Id on Line Multidisciplinary and Psychology Journal

comunicação entre na administração pública entre servidores e empregadores galgando o respeito e a participação, um dos pontos fortes e que sempre funciona é elogiar os colaborados isso exalta a auto estima , já que o funcionário elogiado pelo seus talentos gera satisfação ao empregado e empregador. Ainda a elaboração de um plano de cargos e salários também é uma maneira eficaz de motivar os funcionários e valorizar pelo reconhecimento. O bem estar de um bom ambiente de trabalho contagia a equipe, os clientes e até mesmo o cofre público, já que trabalhando direitinho não atrai prejuízos, ou seja, não paga multas, ao contrário passam a ter o retorno do investimento através dos bons resultados adquiridos ao logo do tempo com a organização e colaboradores. Investir em reinventar incentivando a equipe tenha participação na preserva pela higiene da empresa e incentivar os empregados a serem sempre cordiais com os clientes (o povo), e criar espaços de interação e descanso.

\section{Etapa de Avaliação}

Além de pesquisa bibliográfica, propôs-se uma pesquisa de campo que foi desenvolvida na administração pública. Observando critérios estabelecidos para elaboração e execução, com a finalidade de preservar os princípios éticos da pesquisa com seres humanos. Dessa forma, os critérios de inclusão estabelecidos foram que todos os sujeitos deveriam ser maiores de idade, e que, fossem colaboradores da gestão pública.

\section{Elemento da Pesquisa}

\section{Pergunta $n^{0}$ 1: Existe reconhecimento pelo trabalho desenvolvido:}

$17 \%$ servidores afirmam existir

$49 \%$ servidores afirmam existir de forma esporádica

Pergunta $n^{\circ}$ 2: Quais as chances de crescimento profissional dentro do ambiente de trabalho:

$50 \%$ não enxergam nenhuma chance

$42 \%$ enxergam remotas

08\% consideram a possibilidade de galgar níveis mais altos

Pergunta $n^{0}$ 3: você sente-se motivado pelo exercício de sua atividade profissional:

$50 \%$ estão motivados na maioria das vezes

$25 \%$ declararam que estão sempre motivados

$17 \%$ afirmando que raramente sentem-se motivados

$08 \%$ nunca estar motivados 
Id on Line Revista Multidisciplinar e de Psicologia

Id on Line Multidisciplinary and Psychology Journal

\section{Pergunta $n^{\circ}$ 4: Como você avalia a política de treinamento de pessoal?}

$67 \%$ declararam que a política de treinamento é regular

$33 \%$ que declararam ser péssima.

Pergunta no5: Possui algum tipo de ajuda financeira individual por desempenho ou vantagens adicionais por mérito?

$8 \%$ alcançam reconhecimento

92\% responderam existir pouco para alcançar o valor do reconhecimento devido.

\section{Pergunta n $\mathbf{n}^{0}$ 6: Como você avalia a comunicação entre os níveis hierárquicos da instituição?}

$33 \%$ afirmam ser boa.

$42 \%$ revelam ser regular

$25 \%$ péssima.

Pergunta $n^{0}$ 7: Como você avalia os fatores que afetam o bem-estar dentro da empresa?

$12 \%$ afirmam ser boa.

$30 \%$ revelam ser regular

$58 \%$ péssima.

Pergunta $\mathrm{n}^{\circ}$ 8: A empresa faz reuniões periódicas para medir o clima organizacional, bem como, ouvir sugestões por parte dos colaboradores?

$42 \%$ revelaram que nunca houve

$58 \%$ revelaram que isso raramente acontece

\section{Resultado da Pesquisa}

A pergunta 1, reconhecimento do trabalho desenvolvido em relação ao desempenho e a atividade profissional, demonstrou que a falta de reconhecimento é muito grande, pois apenas $17 \%$ dos servidores entrevistados afirmaram que têm o devido reconhecimento.

A pergunta 2, as chances de crescimento profissional no ambiente de trabalho, apontou também índice negativo de $92 \%$, isso porque não possui um plano que estabeleça desempenho e cumprimento das tarefas por metas e desafios através de promoções e incentivos.

A pergunta 3, A motivação no exercício da atividade profissional, demonstrou positiva por $75 \%$ afirmaram estar motivados no exercício da atividade profissional o que indica que se precisa melhorar alcançando os $17 \%$ do resultado que afirmaram que raramente se sentem motivados e $8 \%$ declararam que nunca estão motivados;

A pergunta 4, Avaliação da política de treinamento de pessoal, os índices positivos de $67 \%$ apontado um entrosamento de colaboradores e gestão quanto ao desenvolvimento de pessoal, sendo 
necessário um trabalho amplo onde se busque mais participação com implantações de programas continuo de qualificação de desenvolvimento de pessoal.

A pergunta 5, Possui algum tipo de ajuda financeira individual por desempenho ou vantagens adicionais por mérito foi negativamente demonstrado por $92 \%$ dos entrevistados aos quais não possuem nenhuma premiação por reconhecimento do trabalho prestado, a falta de metas por desempenho, fato já analisado nas respostas anteriores supracitados.

A pergunta 6, avaliação da comunicação entre os níveis hierárquicos da instituição, apresenta $67 \%$ negativa, cabendo ações estratégicas voltadas à socialização dos sujeitos.

A pergunta 7 ,avaliação dos fatores que afetam o bem-estar dentro da organização apontado por o índice de 58\% onde revelaram ser péssimo, constatando que o ambiente precisa ter um olhar urgente que ofereça segurança, saúde e lazer onde alcancem a satisfação através de boa infra-estrutura, organização e criatividade.

A pergunta 8 , avaliação do clima organizacional e diálogo entre os colaboradores, apresentou $42 \%$ negativo onde afirmaram que nunca houve e $58 \%$ que raramente acontece, sendo claro a necessidade de políticas de qualificação de pessoal, cargos e salários, avaliação de desempenho, incentivos e promoções e avaliação mensal do clima organizacional.

\section{Conclusões}

O estudo fez concluir a relevância da motivação na administração pública como um fator importante no ambiente de trabalho com relação às teorias motivacionais e da pesquisa, pois consiste na influência do comportamento dos funcionários para exercem suas atividades com qualidade, ao qual proporciona um espírito de equipe e uma melhor produtividade no trabalho.

Onde Motivar seus colaboradores é satisfazer algumas de suas necessidades garantindo condições de trabalho satisfatórias não só de maior produção e economia de tempo, mas também em evitar problemas com indenizações trabalhistas.

Podemos afirmar que o salário não é único motivador, mas que existe também no reconhecimento das tarefas através de incentivos e elogios, elevando a auto-estima e sucesso na carreira dos funcionários.

A ampla literatura sobre o tema fator motivacional uma abordagem critica com foco na gestão pública, impossibilita apresentar e discutir todos os modelos teóricos existentes, por tanto recomendamos as teorias e sugestões apresentadas anteriormente. 
Id on Line Revista Multidisciplinar e de Psicologia

Id on Line Multidisciplinary and Psychology Journal

Referências:

BERGAMINI, C. W e BERALDO, D. G. R. Avaliação de Desempenho Humano na Empresa. 4.ed. São Paulo: Atlas, 1988.

BERGAMINI, C. W. Psicologia aplicada à administração de empresas: Psicologia do Comportamento Organizacional. 4. ed. São Paulo: Atlas, 2006.

BERGAMINI, Cecília Whitaker e CODA, Roberto. Psicodinâmica da Vida Organizacional. 2a. ed. - SP: Atlas, 1995.

CASTRO, D. G. A importância da motivação para o comportamento organizacional da empresa Flora Garden. Anápolis: UniEvangélica, 2005. (Monografia).

CHIAVENATO, Adalberto Gestão de Pessoas: O novo papel dos recursos humanos nas organizações. Rio de janeiro: Campus, 1999.

CHIAVENATO, I. Administração de Empresas. Uma abordagem contingencial. São Paulo: McGraw-Hill, 1982.

CHIAVENATO, I. Administração de Recursos Humanos: fundamentos básicos. 4. ed. São Paulo: Atlas, 1999.

CHIAVENATO,Idalberto.Administração nos novos tempos. 6 ed. RIO DE JANEIRO: Campus, 2000.

DUBRIN, Andrew J. Fundamentos do comportamento organizacional. São Paulo: Pioneira Thomson Learning, 2003.

GUIMARÃES, D. C.; MACEDO, H. B. Programas de qualidade de vida no trabalho e as vivências de prazer e sofrimento dos trabalhadores. Anais do XXIX Encontro Nacional de PósGraduação em Administração. Brasília. 2005.

HERING S. de Q. Motivação dos quadros operacionais para a qualidade sob o enfoque da liderança situacional. Dissertação de Mestrado de, Engenharia de Produção-PPGEP, UFSC,1996.

LAWER, Edward E. Motivação nas organizações de trabalho. 3. ed. São Paulo: Atlas, 2000.

LIMONGI-FRANÇA, Ana Cristina. Qualidade de Vida no Trabalho - QVT: conceitos e práticas nas empresas da sociedade Pós-industrial. São Paulo: Atlas, 2004.

MCGREGOR, D.. Os aspectos humanos da empresa. Lisboa, Livraria Clássica Editora, 1970.

MÓDULO III- A Sociedade e a Gestão de Pessoas, Londrina2008.

OLIVEIRA, G.F.; SILVA, R.C.A. e ROLIM, S.G. Análise Bioenergética: uma revisão sistemática da literatura. Id on Line Revista de Psicologia, Julho de 2013, vol.7, n.20, p. 75-96. ISSN 1981-1189. DOI: 10.14295/idonline.v7i20.238. 
Id on Line Revista Multidisciplinar e de Psicologia

Id on Line Multidisciplinary and Psychology Journal

ROBBINS, Stephen Paul. Comportamento organizacional. 11. ed. São Paulo: Pearson Prentice Hall, 2005.

SALES, S. D. Motivação como ferramenta para gestão das universidades federais brasileiras. Florianópolis: UFSC, 2005. (Tese de Doutorado).

TOLEDO, F. Recursos humanos no Brasil: mudanças, crises e perspectivas. São Paulo: Atlas, 1981.

VERGARA, S. C. Gestão de pessoas. 2. ed. São Paulo: Atlas, 2000.

VERGARA, Sylvia Constant. Gestão de pessoas. 2. ed. São Paulo: Atlas, 2000

Como citar este artigo (Formato ABNT):

SOARES, Vanusa B. dos S.; QUEIROZ, Luiz A. B.; CAFFE FILHO, Hesler P. A Importância do fator motivacional no trabaho: uma abordagem crítica Disponível em: http://www.idonlinerevistadepsicologia. emnuven.com.br/id >. Id on Line Revista de Psicologia, Fevereiro de 2016, vol.10, n.29. p. 23-36. ISSN 19811179 .

Recebido: 30/01/2016.

Aceito: 26/01/2016 